\title{
Geriatric care in nursing homes
}

\author{
Chit Wai Wong, FHKAM (Medicine), FHKCP \\ Department of Medicine and Geriatrics, Caritas Medical Centre, Hong Kong
}

Correspondence to: wcw846@ha.org.hk

Geriatric care service has been progressing with time to meet the needs of society. It has extended from hospital-based to community-based in response to the increasing number of elderly people living in nursing homes, owing to the ageing population. Very often, these residents are frail with the burden of chronic medical illness, impaired cognition, polypharmacy, and related geriatric syndromes. Comprehensive multi-disciplinary geriatric services, for example in the form of a Community Geriatric Assessment Team (CGAT) in Hong Kong, enable timely assessment of non-acute ongoing problems among nursing home residents. ${ }^{1,2}$ These services facilitate provision of a management plan or rehabilitation program, so as to preserve health and quality of life. In addition to providing regular medical visit for nursing home residents, CGAT also provides training to care workers to enhance the quality of care in nursing homes. Community geriatric services continue to strengthen by developing programmes to focus on the specific needs of nursing home residents, such as endof-life care, feeding problems, and fall prevention. In this issue, we feature two articles related to preventive programmes in nursing home: one to reduce hospital admission and the other to prevent falls.

Avoidance of hospital admission is a major concern for all health care systems. Hospital admission not only increases health care expenses but is also detrimental to patients owing to the increased risks of functional decline, hospital acquired infection, iatrogenesis, and mortality. Ling et $\mathrm{al}^{3}$ demonstrated that on-site acute geriatric consultation to nursing home residents facilitated early discharge from the emergency department and reduced hospital admissions. However, this approach may not be feasible for some regions or suitable for all health care systems. Options of programmes targeted on common disease entities, such as chronic obstructive airway disease, congestive heart failure, and chest infection, that contribute to significant hospital admission among the nursing home residents may be considered.

Furthermore, nursing home residents are at risk of falls with subsequent serious injuries and hospital admission. Fall prevention in nursing homes remains a challenge as falls are often multifactorial with interaction of personal and environmental factors. ${ }^{4}$ Yoon et $\mathrm{al}^{5}$ provided a comprehensive review on fall prevention interventions and policies in nursing homes in Western countries and Hong Kong. On understanding the benefits and limitations of different interventions, a fall prevention programme adapted for our locality can be developed.

Successful implementation of any programmes for nursing home residents relies on conducting comprehensive multi-disciplinary geriatric assessment to identify who are at risk of a particular condition and the associated risk factors, then deciding the treatment goal, the most beneficial intervention, and the treatment end-point. The programme should be modified according to individual circumstances and reviewed regularly. Such a patient-centred approach definitely helps to meet the needs of residents to improve health outcomes, and it is the general trend in geriatric medicine.

\section{REFERENCES}

1. Chan HW, Wong CP, Liu SH. New frontiers in geriatric service: the community geriatric assessment teams. J Hong Kong Geriatr Soc 1996;7:9-13.

2. Sim TC, Leung EMF. Geriatric care for residents of private nursing homes.J Hong Kong Geriatr Soc 2000;10:84-9.

3. Ling AL, Cheng CT, Liu F, et al. Impact of acute geriatric services for nursing home residents on emergency department presentations and hospitalisation. Asian J Gerontol Geriatr 2018;13:68-73. Crossref

4. Luk JK, Chan TY, Chan DK. Falls prevention in the elderly: translating evidence into practice. Hong Kong Med J 2015;21:165-71. Crossref

5. Yoon GH, Kwan RY, Liu JY, Lai CK. Fall prevention in nursing homes: comparison of local and international guidelines and polices: a systematic review. Asian J Gerontol Geriatr 2018;13:53-62. Crossref 